\title{
SOCIAL AND MENTAL REHABILITATION OF THE PATIENTS WITH THE OBSESSIVE-COMPULSIVE DISORDER AND HYPOHONDRIASIS
}

\author{
Yuliya Chelyadyn, Timur Gonchar, Lyudmila Uralova \\ P.L. Shupyk National Medical Academy of Postgraduate Education, Ukraine \\ E-Mail: chelyadyn.yuliya@gmail.com, kot7916@gmail.com, ogonchar42@gmail.com
}

\begin{abstract}
Nowdays the problems of obsessive-compulsive disorders and hypochondriasis have become quite urgent. The disorders are often encountered both in mental institutions and in general medicine clinics. They are resistant to treatment and there is always a menace of them transforming into a chronic mental illness. So, it's important to deal with the issue of the psychiatric rehabilitation (reintegration into the social environment) of those suffering from said disorders. To achieve good results psycho-social treatment and rehabilitation measures should be taken beginning from the earliest mental treatment stages. However, there are still many unclear and misunderstood points both in design and application of the rehabilitation program. In this study during the years 2012-2016 based on the previous work we have developed the programs for the group of 80 patients with said disorders. The results of the evaluation of the patient's basic functioning after application of the programs are presented in the paper.
\end{abstract}

Key words: coping resource, coping strategy, obsessive-compulsive disorder, hypochondriasis, rehabilitation.

\section{Introduction}

Obsessive-compulsive disorder (OCD) is a disorder that is characterized by haunting thoughts (obsessions) or by repeated actions - rituals (compulsions) or rather by the combination of both.

According to ICD-10 (International Classification of Diseases), the obsessive-compulsive disorder is diagnosed if obsessive thoughts or compulsive actions or both of them are being observed a maximum number of days during two consecutive weeks and are the source of distress and social activity violation. Obsessive symptoms should have the following features:

1. They should be considered as own thoughts and impulses of the diseased;

2. There should be at least one thought or one action that the diseased unsuccessfully tries to resist;

3. The thought about certain action should not by itself be pleasant;

4. The thoughts, images or impulses should repeat themselves and be unpleasant for the person;

5. The diseased person usually understands that the haunting thoughts or actions are excessive or unfounded (Мосолов, 2006). 
The problem of the obsessive-compulsive disorder is quite urgent now. Notwithstanding all the new studies and psychopharmacotherapy methods the treatment of the people with the disorder remains difficult. Studies have shown that the symptomatic manifestations of the disorder are characteristic for the age interval from 10 to 24 years (Rasmussen \& Eisen, 1994).

The presence of the OCD in general population is about $1.5-3 \%$. The disorder occurs approximately equally in men and women, predominantly in adolescents (one-third of the cases below 15 years) (Rasmussen \& Tsuang, 1984; Rasmussen \& Eisen, 1992).

Obsessive-compulsive disorder often is accompanied by other mental disorders (comorbidity): recurrent depression (50-70\%), somatoform disorders (30-40\%), specific or simple phobias (20-30\%), panic disorders (20-30\%), social phobia (20-25\%), schizophrenia (10-15\%), and also by Tourette syndrome, Sydenham's chorea, postencephalitic parkinsonism where obsessive thoughts occur in 35-50\% patients (DSM-IV, 1994). Approximately 20-30\% people with OCD have the tic.

Hypochondriasis, taking into account its prevalence, is of importance not only from the narrow special point of view (Rief \& Rojas, 2007; Noyes, Stuart \& Langbehn, 2003) but also from the general medical point (Martin \& Jacobi, 2006; Fergus \& Valentiner, 2009). This problem is urgent both for psychiatrists and for the wide range of other medical specialties and clinical psychologists involved in the field of psychosomatic medicine. According to epidemiologic evidence, the prevalence of hypochondriasis is in the range $4.5-20 \%$ (Ristner, Modai \& Endicott, 2000; Creed \& Barsky, 2004). The estimated values for the incidence of non-delusional hypochondriasis in mental institutions also lie inside rather wide boundaries. The value of the said indicator within general medical network rises significantly and varies from 19.7\% (Goldberg, Gater, Sartorius, Piccinelli, Gureje, \& Rutter, 1997) to 58\% (Hansen, Fink, Frydenberg, de Jonqe, \& Huyse, 2001; Fink, Hansen \& Oxhøj, 2004). Modern authors (Hollifield \& Finlay, 2014) claim that such variance in statistics pointing at incompleteness of the problem understanding is connected with the lack of agreement in defining diagnostic criteria and non-delusional hypochondriac states (Noyes, Langbehn, Happel \& Stout, 2001; Creed \& Barsky, 2004; Mayou, Kirmayer, Simon, Kroenke \& Sharpe, 2005). So, these days the problems of obsessive-compulsive disorder and hypochondriasis are of importance. Despite the relatively shallow level of mental activity affection, OCD and hypochondriasis are resistant to the treatment and show tendency to convert to chronic disease with considerable negative social and economic outcomes (Amir, Freshman \& Foa, 2000). Hence a significant role played by psycho-social rehabilitation.

There are many models of rehabilitation and views on its implementation. However, all the researchers and the practitioners agree that the ultimate goal thereof should be reintegration (return) of the patient into society. And in doing so, the patients should feel themselves no less valid society members than other citizens. So, the goal of the rehabilitation may be defined as an improvement of the quality of life and social functioning for the people with mental disorders by means of overcoming social estrangement, and establishing more active life and social attitudes (Чубко \& Романченко, 2012).

Character and frustration traits inherent to the patient's personality play an important role in adaptation to stressors. Psychotherapeutic correction and then development and implementation of the psychological rehabilitation model on different levels will make it possible to decrease the maladjustive defensive activity, to recover disturbed personality relationships, and to recognize and resolve conflicts. An analysis of interrelations between personality traits, specific features of the OCD and those of hypochondriasis is necessary to develop differentiated and adequate treatment of the patients. Such treatment will make it possible to improve their mental state, to reduce clinical manifestations of the disease, and also to raise considerably the effectiveness of the biological outcome, widen the possibilities to develop personal medicosocial rehabilitation program (skills training, skills programming, resources coordination, and resources modification).

Currently, the psycho-social therapy and the psycho-social rehabilitation are playing an increasing role within the mental health care; these are being viewed as an independent treatment and rehabilitation field in psychiatry (Гурович, Шмуклер, \& Строжакова, 2004; Bustillo, Lauriello, Horan \& Keith, 2001). Special attention is being paid to the continuity and to following 
the stages of the psycho-social influence throughout all the patient management time (Liberman

\& Robert, 1988). Thereby the psycho-social treatment and rehabilitation measures should be taken beginning from the earliest mental treatment stages and continue till the full restoration of the patient's social autonomy is achieved (Гурович \& Ньюфельдт, 2007). Application on all the stages of mental health care along with the correct psychopharmacology of adequate psycho-social treatment and rehabilitation measures is an urgent task of the now-days psychiatry; it requires dedicated studies and development of approaches for the further implementation (Краснов, Гурович, Мосолова \& Шмуклер, 2007; Brugha, 1995; Hemsley \& Murray, 2000).

So, the problem of the rehabilitation of the people suffering from the OCD and hypochondriasis comes to the forefront not only in psychiatry but also in general medicine; it's also important from the state economy point of view in what concerns payments of financial assistance to those who have a disability group assigned.

As of now, the approaches to medical-social rehabilitation of the people with the OCD and hypochondriasis are insufficiently developed. Unfortunately, currently many mental rehabilitation programs utilize rather the technologies of the treatment and not the methods of the rehabilitation itself. The goal of the rehabilitation is to improve person's functioning in certain environment; rehabilitation interventions may occur without substantiating them with some causality theory; rehabilitation measures aim at person's current functioning and at future problems and not at the disease origins; the rehabilitation analysis is focused on saving the patient's capabilities and on the help from without, on the skills programming, resources modification, etc. (Anthony, Cohen, Frakas, \& Gagne, 2002).

\section{Methodology of Study}

\section{The Aim of the Study}

The aim was to develop differential psychological and social rehabilitation program for people with obsessive-compulsive disorder and with hypochondriasis.

\section{Study Materials and Methods}

During years 2012-2016 on the basis of the City Clinical Hospital of the city of IvanoFrankivsk, Territorial Medical Association (TMA) "Psychiatry", and municipal psycho-neurological clinic \#4 in Kiev 80 patients with the OCD of the neurotic type were examined, 15 of them had hypochondriasis. In the group, there were 39 (61.9\%) men and 24 (38.1\%) women. The average age for those who have undergone hospital or outpatient treatment was 31.6 \pm 11.0 years. Persons with the age less than 18 years and more than 65 years, those with heavy somatic pathology, with serious central nervous system lesions were eliminated from the study. Professional and family status indicators for the nosologic group show degradation of the social adaptation level. On the other hand, at the time of the examination only 21 patients $(33.3 \%)$ were unemployed, 8 (12.7\%) were officially disabled. 16 persons $(25.3 \%)$ were married or lived with the permanent partner which may indicate social withdrawal, violation of interpersonal contacts. Obsessive-compulsive symptoms were first observed at the average age of $22.0 \pm 9.8$ years, the average interval of the disease was about 6.6 years.

The main methods of investigation were clinical-psychopathological method; psychological method - the scales and questionnaires: WHODAS 2.0 (World Health Organization Disability Assessment Schedule) to estimate general functioning, psychological test to estimate personality, MMPJ, PANSS scale, Hamilton depression and anxiety scale; statistical method (descriptive statistics, Student t-criterion, correlation analysis and multifactor analysis). The criterion of statistical significance was chosen to be $\mathrm{p}<0.05$. All calculations were made using the application package SPSS.

The OCD manifestations are significantly polymorphic. Hence, on this stage of the study, in order to differentiate between clinically meaningful subtypes of the disorder, one performs clinically-statistical analysis of obsessions and an estimation of the occurrence of the disease. 
The tool here is the Y-BOCKS scale (obsessive-compulsive scale). Also, to define the goals and further medical and rehabilitation correction, the method of the mental diagnosis of the ordered behavior in the stressful and problematic personal situations was used (СВП, 2008 Санкт-Петербург). In the study we utilized the scales to detect hypochondriasis: the scale for the independent patient work - Whitley Index (WI), Multidimensional Inventory of Hypochondriasis (MIHT), and the Hypochondriasis Yale-Brown Obsessive Compulsive Scale Modified (H-YBOCS-M1).

\section{Results of Study}

The results of the scale application were as follows: $12.7 \%$ - easy course of the OCD, $56.2 \%$ - moderate course, $31.0 \%$ - severe course, and $0.1 \%$ - extremely severe course of the OCD.

As a result of statistical processing of the data four factors were allocated:

1. Control of completeness of action, compulsions of order, symmetry and repletion $(39.9 \%)$; clinical interpretation of the result demonstrates that it reflects one of the main OCD worries - the perception of "incompleteness" of action. Said worry typically provokes patient anxiety and leads to compulsions and repetitions rituals.

2. The factor of obsessive safety - it's an obsession of infection (42.3\%).

3. The factor of obsessive prohibited incitements - these are certain religious obsessions of the contrast type (12.1\%).

4. The factor of obsessive appropriation - represented by the symptoms of obsessive gathering and collecting (5.7\%).

The study revealed that in given sample prevail the strategies of the search for social support and that of positive reevaluation (58\%).

In essence, the patients evaluate their own resources as insufficient, show the tendency to experience helplessness and incapacity which leads to the increased need for support from the others and also to an attempt to overcome the negative experience with the problem at the cost of the positive reconsideration of the latter, of accepting it as an incentive for personal growth.

In $46 \%$ of the examined dominate the strategies of taking the responsibility and that of escape-avoidance.

Moderate usage of the said strategies reflects the person's drive for the understanding of the dependency between own actions and consequences, readiness to analyze own behavior and search for the sources of the real problems in own errors.

The strategy of escape-avoidance implies attempts to overcome negative personal worries caused by the difficulties with the reaction of avoidance: denial of the problem, fantasizing, expectations justification, distraction, etc.

In $87 \%$ of the examined the strategy of self-control implies attempts to overcome negative experiences at the cost of the purposeful emotions repression and restraint, of minimization of their effect on the perception of the situation, of the selection of the behavior strategy, of the tight control over the behavior.

Along with the data from the study, we also utilized the earlier developed notion of the stages of the psychiatric rehabilitation (Гончар, 2011). There are two such stages - the in-patient stage and the out-patient stage. On the first stage, along with the intensive, stabilizing treatment to avoid the relapses, great importance was given to the formation of the rehabilitation preparedness.

Preparedness evaluation helps patients to estimate how strong their determination to take part in the rehabilitation measures is. If in the process they decide that they are not ready for rehabilitation, the build-up will help them to enhance, and to raise the expectations level in relation to rehabilitation capabilities. Preparedness evaluation helps patients to "judge themselves", whether it makes sense for them to ask for rehabilitation help in given environment created by the conditions of life, work, education, by the social conditions. Rehabilitation preparedness is an indicator estimating determination and interest of the participants and not their potential to achieve positive results in rehabilitation. 
Special rehabilitation preparedness questionnaire was used to make estimates in five different directions (Anthony, Cohen, Frakas, \& Gagne, 2002):

1. Desire for change indicated by the lack of success or satisfaction in given environment.

2. Adherence to change expressed in the firm belief that the changes are desirable and possible.

3. Closeness of personal relations connected to the relationships with someone who supports given person in her desire to participate in the rehabilitation.

4. Self-awareness, namely awareness of the personal values and interests that are somehow connected to the given environment.

5. Awareness of peculiarities of different environments which is an understanding of the traits, ways of life, work, education and social conditions inherent in the environment where given person tries to achieve success and the feeling of the satisfaction with life.

The questionnaire also reserves space to describe the measures towards the enhancement of the preparedness level, i.e. the motivational or educational measure that can enhance personal preparedness. Such measures make it clear whether or not to continue participating in the rehabilitation process.

Family therapy together with the program of psycho-education and social skills trainings were used to build the rehabilitation preparedness. The therapy was carried out in the gestalt approach style using the technics of the neurolinguistic programming.

The goal of the psycho-education was to develop an integrative program intended, on one hand, for the patients themselves and, on the other hand, for the members of their families and those near to them. The program formed in patients and their family members an adequate knowledge about mental diseases and stimulated them to actively participate in the rehabilitation measures.

At the outpatient stage, against the background of supportive therapy, the rehabilitation diagnosis was defined; the goals of the rehabilitation were set, the planning of the skills development, training, and programming was conducted.

The rehabilitation diagnosis is used to evaluate the patient's skills and the types of support in the environment chosen by him - it may be life, education, social connections support, and work. The diagnosis has three components: the final rehabilitation goal, functional evaluation and estimation of supporting resources. The final rehabilitation goal defines specific environment chosen by the patient for his life activity. The goal is being determined after several interviews with the patient; in the course of the interviews his needs and alternative environments are being examined.

The definition of the general rehabilitation goal included an evaluation of the rehabilitation preparedness and selection of the goal itself, an inventory of the most important skills, an estimation of the degree of the utilization of opportunities. To these ends the dedicated entry form was used.

In the study group therapy besides the mental education and family therapy we used mental correction with the gestalt approach, cognitive-behavioral therapy, the technics of the short-time positive therapy, the behavioral approaches: "implosive therapy", "systematic desensitization", and "rehearsal of behavior".

The therapy that should be conducted for a long time and with intensity is, together with the biological methods, a necessary condition for the successful treatment of the patients with OCD on all the stages. The most effective is the behavioral therapy (gradual increase of exposure to the trigger situations to achieve desensitization). The effect of the behavioral therapy treatment persists for several months and even years. It's different with the drug therapy; in many cases after the latter is cancelled the exacerbation of the OCD symptoms is being observed. Typically the compulsions are treated better than obsessions; in the compulsions case the behavioral 
therapy is being used, in the case of obsessions - the cognitive therapy, although such division is of more theoretical nature, the practical usage implies the cognitive-behavioral therapy.

An evaluation of basic functioning after medico-social rehabilitation has shown significant decrease in the social withdrawal, increases in the need for self-care; in partake in family life, in care about children, in professional life, in awareness about social life; out of house interpersonal relations enhanced also (Table 1).

Table 1. Basic functioning indicators of the main group before and after the rehabilitation measures according to the basic functioning scale.

\begin{tabular}{lcc}
\hline \multicolumn{1}{c}{ Symptoms } & Before treatment & After treatment \\
\hline Social withdrawal & $4.51 \pm 0.11$ & $0.04 \pm 0.01$ \\
Self-care & $3.73 \pm 0.07$ & $0.11 \pm 0.01$ \\
Partake in family life & $4.50 \pm 0.07$ & $0.16 \pm 0.03$ \\
Marriage attitude & $4.48 \pm 0.09$ & $0.30 \pm 0.02$ \\
Interest and care about children & $4.41 \pm 0.05$ & $0.25 \pm 0.02$ \\
Sexual role & $4.30 \pm 0.12$ & $0.50 \pm 0.01$ \\
Difficulties in interpersonal relations & $4.17 \pm 0.09$ & $0.33 \pm 0.03$ \\
Professional role & $4.44 \pm 0.08$ & $0.09 \pm 0.01$ \\
Interest in employment & $4.57 \pm 0.06$ & $0.09 \pm 0.01$ \\
Interest and knowledge about social activity & $4.60 \pm 0.07$ & $0.09 \pm 0.01$ \\
\hline
\end{tabular}

\section{Conclusions}

Using the method of psychological diagnostics of the ordered behavior in stressful and personally problematic situations and the scale of perception of the social support to define the goals for further therapeutic and rehabilitation correction this study has shown that behavior of the patients with OCD is dominated by the coping strategies directed mostly at the personal discomfort reduction and not at the problem situation resolution. The main coping resources are support from the family, from the people who are important for the person, and from the social institutions.

Such personal reaction stereotype may be the basis of the patient's mental adaptation disturbance and is an important "target" for the mental corrective influence. All said makes it possible to carry out cross analysis of the four singled out factors of the coping resources determination and coping strategies utilization correspondingly for each factor. This enables differentiated approach to treatment and rehabilitation.

The programs of the medical-social rehabilitation allow to enhance considerably the social functioning, to improve the quality of life.

\section{References}

Amir, N., Freshman, M., \& Foa, E.B. (2000). Family distress and involvement in relatives of obsessivecompulsive disorder patients. Journal of Anxiety Disorders, 14 (3), 209-17.

Anthony, W., Cohen, M., Frakas, M., \& Gagne, C. (2002). Psychiatric rehabilitation. Boston, MA: Boston University, Center for Psychiatric Rehabilitation.

Brugha, T. S. (1995). Depression undertreatment: Lost cohorts, lost opportunities? Psychological Medicine, 25, 3-6.

Bustillo, J., Lauriello, J., Horan, W., \& Keith, S. (2001). The psychosocial treatment of schizophrenia: An update. American Journal of Psychiatry, 158 (2), 163-75. 
Creed, F., \& Barsky, A. (2004). A systematic review of the epidemiology of somatization disorder and hypochondriasis. Journal of Psychosomatic Research, 56 (4), 391-408.

Fergus, T. A., \& Valentiner, D. P. (2009). Reexamining the domain of hypochondriasis: Comparing the Illness Attitudes Scale to other approaches. Journal of Anxiety Disorders, 23 (6), 760-766. doi: 10.1016/j.janxdis.2009.02.016.

Fink, P., Hansen, M. S., \& Oxhøj, M. (2004). The prevalence of somatoform disorders among internal medical inpatients. Journal of Psychosomatic Research, 56 (4), 413-418.

Goldberg, D. P., Gater, R., Sartorius, N., Piccinelli, M., Gureje, O., \& Rutter, C. (1997). The validity of two versions of the GHQ in the WHO study of mental illness in general health care. Psychological Medicine, 27 (1), 191-197.

Hansen, M. S., Fink, P., Frydenberg, M., de Jonqe, P., \& Huyse, F. J. (2001). Complexity of care and mental illness in medical inpatients. General Hospital Psychiatry, 23 (6), 319-325.

Hemsley, D., \& Murray, R. M. (2000). Commentary: Psychological and social treatments for schizophrenia: Not just old remedies in new bottles. Schizophrenia Bulletin, 26 (1), 145-151.

Hollifield, M., \& Finlay, L. (2014). The boundary between hypochondriasis, personality dysfunction, and trauma. Current Psychiatry Review, 10 (1), 34-43.

Liberman, R. P., \& Robert, P. (Eds.) (1987). Psychiatric rehabilitation of chronic mental patients. Washington, DC: American Psychiatric Press.

Martin, A., \& Jacobi, F. (2006). Features of hypochondriasis and illness worry in the general population in Germany. Psychosomatic Medicine, 68 (5), 770-777.

Mayou, R., Kirmayer, L. J., Simon, G., Kroenke, K., \& Sharpe, M. (2005). Somatoform disorders: Time for a new approach in DSM-V. American Journal of Psychiatry, 162, 847-855.

Noyes, R., Langbehn, D. R., Happel, R. L., \& Stout, L. R. (2001). Personality dysfunction among somatizing patients. Psychosomatics, 42 (4), 320-329.

Noyes, R., Stuart, S., \& Langbehn, D.R. (2003). Test of an interpersonal model of hypochondriasis. Psychosomatic Medicine, 65 (2), 292-300.

Rasmussen, S. A., \& Tsuang, M. T. (1984). The epidemiology of obsessive compulsive disorder: A review. Journal of Clinical Psychiatry, 45, 450-457.

Rasmussen, S. A., \& Eisen, J. L. (1992). The epidemiology and clinical features of obsessive compulsive disorder. Psychiatric Clinics of North America, 15 (4), 743-758.

Rasmussen, S. A., \& Eisen, J. L. (1994). The epidemiology and differential diagnosis of obsessive-compulsive disorder. Journal of Clinical Psychiatry, 55, Suppl., 5-10.

Rief, W., \& Rojas, G. (2007). Stability of somatoform symptoms - implications for classification. Psychosomatic Medicine, 69 (9), 864-869.

Ristner, M., Modai, E., \& Endicott, J. (2000). Differences of quality of life domain and psychopathologic and psycho-social factors in psychiatric patients. Journal of Clinical Psychiatry, 61 (11), 880-889.

Гончар, Т. О. (2011). Медико-соціальна реабілітація пацієнтів, які страждають на шизофренію, в процесі надання стаціонарної та амбулаторної психіатричної допомоги в примусовому порядку [Medical-social rehabilitation of patients with schizophrenia while providing for coercive in- and out-patient treatment]. (unpublished $\mathrm{PhD}$ thesis). Київ: Науковий світ.

Гурович, И. Я., Шмуклер, А. Б., \& Строжакова, Я. А. (2004). Психосоциальная терапия и психосоииальная реабилитаиия в психиатрии [Psychosocial therapy and psychosocial rehabilitation in psychiatry]. Москва: Медпрактика.

Гурович, И. Я., \& Ньюфельдт, Г. О. Г. (Ред.) (2007). Современные тендениии развития и новые формы психиатрической помощи [Modern tendencies and new forms of psychiatric care]. Москва: Медпрактика.

Краснов, В. Н., Гурович, И. Я., Мосолова, С. Н., \& Шмуклер, А. Б. (2007). Психиатрическая помощь больным шизофренией [Psychiatric care of the patients with schizophrenia]. Москва: Медпрактика-М. 
84 психіатричної допомоги [The role and place of psy system]. Heŭponews, 3, 69-72.

Accepted. December 26, 2016

Yuliya Chelyadyn Assistant, P.L. Shupyk National Medical Academy of Postgraduate

Education, Kyiv, Ukraine.

E-Mail: chelyadyn.yuliya@gmail.com

Timur Gonchar Dr., Associate Professor, P.L. Shupyk National Medical Academy of Postgraduate Education, Kyiv, Ukraine.

E-mail: kot7916@gmail.com

Lyudmila Uralova
Dr., Associate Professor, P.L. Shupyk National Medical Academy of Postgraduate Education, Kyiv, Ukraine.

E-mail: ogonchar42@gmail.com 